\title{
LA RESOCIALIZACIÓN COMO FIN DE LA PENA - una frustración en el sistema penitenciario y carcelario colombiano ${ }^{1}$ A RESSOCIALIZAÇÃO COMO FINAL DA PENA - uma frustração no sistema penitenciário e prisional colombiano
}

\author{
Norberto Hernández Jiménez *
}

\begin{abstract}
En este trabajo, se analiza la resocialización como fin principal de la pena privativa de la libertad en Colombia, durante su fase de ejecución. Para esto, se contextualiza la difícil situación por la que atraviesa el sistema penitenciario y carcelario colombiano que, conforme a lo declarado por la Corte Constitucional, se adecúa a un estado de cosas inconstitucional, donde la dignidad humana de las personas privadas de la libertad se encuentra seriamente comprometida. Dentro de esta realidad, que involucra un marcado hacinamiento carcelario, que, a su vez, propicia un ambiente de violencia, corrupción y desigualdad, la oferta y el acceso a los programas de resocialización son limitados, lo que impide la rehabilitación del individuo. La prueba de fuego en busca del cumplimiento de este fin no es superada, al observar como un gran porcentaje de los reclusos vuelve a prisión, dentro del fenómeno de la reincidencia.

Palabras Clave: Resocialización. Rehabilitación. Fines de la pena. Hacinamiento carcelario. Reincidencia.

Neste trabalho, analisa-se a ressocialização como a finalidade principal da pena privativa de liberdade na Colômbia, durante sua fase de execução. Para isso, contextualiza-se a difícil situação que o sistema penitenciário e carcerário colombiano atravessa, o qual, conforme foi declarado pela Corte Constitucional, se caracteriza por uma situação institucional em que a dignidade humana das pessoas privadas de liberdade se encontra seriamente comprometida. Dentro dessa realidade, que comporta uma significativa superlotação carcerária, a qual, por sua vez, propicia um ambiente de violência, corrupção e desigualdade, a oferta e o acesso aos programas de ressocialização são limitados, o que impede a reabilitação do indivíduo. O desafio da busca do cumprimento dessa finalidade é não superado, pois se observa que uma grande percentagem dos reclusos volta para a prisão, configurando o fenômeno da reincidência.
\end{abstract}

PalAvras-Chave: Ressocialização. Reabilitação. Finalidades da pena. Superlotação carcerária. Reincidência.

\section{INTRODUCCIÓN Y HORIZONTE METODOLÓGICO}

Una vez proferida la sentencia contentiva de una pena privativa de la libertad y en el evento que la persona afectada con la decisión adversa a sus intereses no haya sido beneficiada con alguna de las modalidades que permiten su excarcelación, aquella deberá ser recluida en un establecimiento de penitenciario en

\footnotetext{
* Universidad Libre y Universidad de los Andes Carrera 7, n. 22-86, Piso 3. Bogotá. n.hernandez29@ uniandes.edu.co

${ }^{1}$ El presente artículo fue desarrollado durante la estancia de investigación (2015-2016) en la Universitat Pompeu Fabra (Barcelona), en virtud de la pasantía del doctorado en derecho, financiada por la Universidad de los Andes (Bogotá). Debo agradecer a la Universitat Pompeu Fabra por brindarme un ambiente propicio para la investigación y escritura de este documento, junto con una biblioteca extraordinaria: El dipòsit de les aigües.
}

calidad de condenada. La legislación nacional ${ }^{2}$ establece que, desde este momento - que hace parte de la fase de ejecución de la pena -, se tendrá en cuenta la prevención especial y la reinserción social, siendo el fin fundamental, en este escenario, la resocialización. Aunque este objetivo no está consagrado constitucionalmente como ocurre en otras latitudes, ${ }^{3}$ el principio de resocialización es consustan-

${ }^{2}$ Cfr. artículos $4^{\circ}$ del Código Penal (en adelante CP) y $9^{\circ}$ del Código Penitenciario y Carcelario (en adelante CPC).

${ }^{3}$ En este aspecto, es preciso exaltar la consagración constitucional española, en cuanto a la función de reeducación y reinserción penal (artículo 25.2 Constitucional), a pesar del obstáculo edificado por la jurisprudencia constitucional, al interpretar este precepto Para un análisis completo sobre el tema, ver Urías (2001). Considera este autor que la jurisprudencia en torno a este aspecto comienza en un auto de 1984, en donde se advierte que el mandato constitucional del artículo 25-2 solo es una guía para orientar la política penal y penitenciaria, pero que de allí no se derivan derechos subjetivos (Urías, 2001, p. 57). Ver también las siguientes providencias: ATC 780/1986; STC 2/1987; STC 81/1997; STC 75/1998 y STC 91/2000]. Por su parte, el artículo 27-3 de la Constitución Italiana contempla también que las penas deberán encaminase a la reeducación del condenado, existiendo interpretaciones del Tribunal Constitucional que tampoco favorecen la consagración constitucional (Urías, 2001, p. 50). 
cial al esquema de Estado Social de Derecho implementado en la Constitución Política de 1991 (Rueda, 2010, p. 137). De lo anterior se desprende que, dentro de los modelos punitivos para la elección del castigo, Colombia siguiendo el mandato del Pacto Internacional de Derechos Civiles y Políticos (artículo 10-3), que se integra a nuestra Constitución por vía del bloque de constitucionalidad -, adopta un estándar ideológicamente dirigido hacia la rehabilitación del penado, buscando que el individuo no vuelva a delinquir en el futuro, para lo cual se deben atacar los factores específicos que lo vinculan con la comisión de delitos (Cid, 2009, p. 30).

Sea oportuno advertir que el modelo rehabilitador excluye la prisión como primera opción (Cullen; Gilbert, 1981 apud Cid, 2009, p. 30), atendiendo a que privilegia la resocialización del individuo, lo cual ocurre de mejor manera en libertad, dejando aquella reservada a la imposibilidad de realizar el tratamiento rehabilitador sin el internamiento.

La aplicación del modelo rehabilitador en Colombia es preponderantemente intramural, lo cual se adscribe a la paradoja de pretender educar para la libertad con ausencia de esta (Mir Puig, 1989, p. 38). En esta misma corriente, Zaffaroni (apud Carranza, 2012, p. 46) asimila la imposibilidad de socializar la vida en liberస్ tad dentro de la prisión con la enseñanza de la đ natación en una piscina sin agua. También Garland (2005, pp. 81-82 y 86), al describir las finaconsideraba a la prisión como contraproducente para la reforma del sujeto y su corrección.

Matthews (2011, p. 330), citando a Cullen y Gilbert (1982), resalta las siguientes características de este modelo:

1. La rehabilitación es el único fin de la pena que obliga al Estado a ocuparse de las necesidades y bienestar de los presos;

2. La ideología de la rehabilitación supone una racional respuesta a la idea conservadora de que el incremento de la presión punitiva reduce el crimen; lidades de la pena dentro del welfarismo penal,
3. La rehabilitación continúa recibiendo un considerable apoyo por la opinión pública como uno de los principales objetivos del sistema de En relación con el principio de resocialización, ha señalado nuestra Corte Constitucional que: "Es imperioso recordar que el esfuerzo por la resocialización del delincuente y por su incorporación a la vida en sociedad después de su castigo se traduce en beneficios para la comunidad. Por el contrario, abandonar tal enfoque hace que el sistema penitenciario y carcelario se convierta en un sistema multiplicador de conflictos que genera más y "mejores" delincuentes (la cárcel como universidad del delito), lo que finalmente termina siendo más costoso para el conglomerado social" (Sentencia T-762 de 2015, M.P. Gloria Ester Ortiz Delgado). ${ }^{4}$ En esta misma providencia, más adelante, se enfatiza que, si no se permite la resocialización real de los condenados, no se reduce la reincidencia.

Para llevar a cabo este mandato de optimización, deben brindarse algunas condiciones mínimas que se desprenden de las interpretaciones de la Carta Internacional de Derechos del Comité de Derecho Humanos de Naciones Unidas ${ }^{5}$ y las interpretaciones de la Carta Interamericana de Derechos Humanos hechas por la Comisión Interamericana de Derechos Humanos, ${ }^{6}$ que son impostergables y, por ende, de inmediato e imperativo cumplimiento. Estos requerimientos se relacionan, a continuación:

1. Derecho de los reclusos a ser ubicados en locales higiénicos y dignos;

2. Derecho de los reclusos a contar con insta-

${ }^{4}$ Las referencias que, dentro de este texto, se hagan a las decisiones judiciales (sentencias) precedidas por los literales C- y T- corresponden a sentencias de constitucionalidad y de tutela, respectivamente, proferidas por la Corte Constitucional de Colombia. Las siglas M.P. se utilizan para designar al Magistrado que elaboró la ponencia o el proyecto de fallo.

${ }^{5}$ Cfr. Caso de Mukong contra Camerún, 1994, citado en la sentencia T-388 de 2013, M.P. Maria Victoria Calle Correa.

${ }^{6}$ Cfr. Casos de Thomas (J) contra Jamaica, párrafo 133, 2001; Baptiste contra Grenada, párrafo 136, 2000; Knights contra Grenada, párrafo 127, 2001; y Edwards contra Barbados, párrafo 195, 2001, citados en la sentencia T-388 de 2013, M.P. Maria Victoria Calle Correa. 
laciones sanitarias adecuadas a sus necesidades y al decoro mínimo propio de su dignidad humana;

3. Derecho de los reclusos a recibir ropa digna para su vestido personal;

4. Derecho de los reclusos a tener una cama individual con su ropa de cama correspondiente en condiciones higiénicas;

5. Derecho de los reclusos a contar con alimentación y agua potable suficiente y adecuada;

6. Derecho a tener una adecuada iluminación y ventilación del sitio de reclusión;

7. Derecho a recibir implementos necesarios para el debido aseo personal.

8. Derecho de los reclusos a practicar, cuando ello sea posible, un ejercicio diariamente al aire libre;

9. Derecho de los reclusos a ser examinados por médicos a su ingreso al establecimiento y cuando así se requiera;

10. Derecho de los reclusos a recibir atención médica constante y diligente;

11. Prohibición de las penas corporales y demás penas crueles, inhumanas o degradantes;

12. Derecho de los reclusos a acceder a material de lectura;

13. Derechos religiosos de los reclusos.

Teniendo como base lo anterior, el presente trabajo analiza las condiciones en las que se encuentra el sistema, así como el funcionamiento del tratamiento penitenciario en Colombia, con miras a establecer si aquellos son aptos para alcanzar el principio rector de la resocialización (Rueda, 2010, p. 135). Para esto, (i) se describe la situación penitenciaria colombiana junto con una breve mirada comparada con el caso español, fruto del trabajo de campo en las cárceles de ambos países; luego las (ii) características del tratamiento penitenciario que inicia con el ingreso del individuo a prisión, para inmediatamente después, (iii) ahondar, en el estudio de la resocialización en este contexto, con los diferentes programas ofertados, los beneficios a favor del penado y los índices de reincidencia registrados.

Para este fin, se acude al análisis cuan- titativo a partir de estadísticas oficiales (Larrauri, 2015, p. 43), teniendo siempre presente las limitaciones que lleva consigo este método y la fiabilidad de los datos, que son asumidos con cautela y, por ende, confrontados con la poca información existente, expuesta tanto por organismos públicos de estirpe independiente (Corte Constitucional ${ }^{7}$ y Defensoría del Pueblo ${ }^{8}$ ), como por particulares - entre estos la academia -, que complementan los primeros y, en algunos casos, los contrastan. Los documentos oficiales fueron obtenidos de las bases de datos de la Corte Constitucional, ${ }^{9}$ el Departamento Nacional de Planeación, ${ }^{10}$ el Ministerio de Justicia y del Derecho ${ }^{11}$ y el Instituto Nacional Penitenciario y Carcelario (en adelante INPEC), ${ }^{12}$ este último con estadísticas actualizadas a 30 de abril de 2016. ${ }^{13}$ Por otra parte, el informe estadístico de marzo de 2016 y el informe de rendición de cuentas del año 2014, ambos del INPEC, fueron suministrados por el coordinador del Grupo de Derechos Humanos de la Dirección General de esa entidad. ${ }^{14}$ En ${ }^{7}$ La Corte Constitucional pertenece a la Rama Judicial del Poder Público en Colombia y es una corporación a la que el constituyente primario le confió la guarda de la integridad y supremacía de la Constitución Política. A pesar de hacer parte del Poder Público, su actuación es independiente.

${ }^{8}$ La Defensoría del Pueblo es la entidad encargada de la promoción, el ejercicio y la divulgación de los derechos humanos en Colombia. Acorde con el artículo 281 de la Constitución Política (modificado por el acto legislativo 2 de 2015), el Defensor del Pueblo adquiere una autonomía frente al Procurador General de la Nación.

${ }_{9}^{9}$ Documentos disponibles on line: < http://www.corteconstitucional.gov.co/relatoria/> . Acceso en: 20 mayo 2016.

${ }^{10}$ Documentos disponibles on line:<https://colaboracion. dnp.gov.co/CDT/Conpes/Econ\%C3\%B3micos/Pol\%C3\%ADtica\%20penitenciaria\%20y\%20carcelaria.pdf $>$. Acceso en:_20 mayo 2016.

11 Documento disponible on line: <https://www.minjusticia.gov.co/Portals/0/sala\%20de\%20prensa/documentos/ Lineamientos\%20sistema\%20penitenciario\%20\%20Consulta\%20WEB.pdf > . Acceso en: 20 mayo 2016. (.

${ }^{12}$ Dentro de los parámetros de descentralización que rigen la estructura administrativa en Colombia, el INPEC es un establecimiento público adscrito al Ministerio de Justicia y del Derecho, al cual se encuentra encomendada la función de administrar el sistema penitenciario y carcelario.

${ }^{13}$ Documentos disponibles on line: <http://www.inpec.gov. co/portal/page/portal/Inpec/Institucion/Estad\%EDsticas/Estadisticas/Estad\%EDsticas > . Acceso en: 20 mayo 2016.

${ }^{14}$ Agradezco a Pedro Elías Castañeda Quitián haberme facilitado esta información que, sumado a la tecnología de la información, hizo posible acortar la distancia entre Barcelona y Bogotá, permitiendo el recaudo y análisis de estos 
lo que respecta a los informes de los organismos particulares fueron obtenidos a través de la consulta en las páginas web de los mismos. ${ }^{15}$

Por su parte, en el análisis de la situación carcelaria se emplea una metodología cualitativa, fruto de la observación participante en las cárceles colombianas durante más de cuatro años y su confrontación superficial con una visita realizada a un establecimiento de reclusión en la ciudad de Barcelona.

\section{LA SITUACIÓN PENITENCIARIA COLOMBIANA Y UNA BREVE MI- RADA COMPARADA CON EL CON- TEXTO ESPAÑOL}

En las últimas décadas, las cárceles colombianas han sido el escenario propicio para el debate constitucional sobre el respeto de los derechos fundamentales de los reclusos, dentro de un ambiente que se encuentra en crisis (Iturralde, 2011, p. 112). ${ }^{16}$ Tanto en sentencias judiciales como en informes de organismos oficiales y particulares, se ha descrito la difícil situación por la que atraviesan los establecimientos de reclusión, cuyo índice de hacinamiento supera el $56 \%,{ }^{17}$ frente a los cupos carcelarios existentes.

En estas condiciones, no solo se dificul-

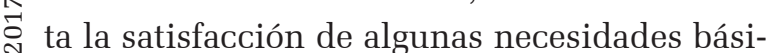
¿ cas, relacionadas con el espacio, la alimentación y, en general, el modo de subsistencia, sino is que, además, se entorpece el cumplimiento de la resocialización como fin primordial dentro 品 de la fase de ejecución de la pena privativa de $\stackrel{2}{i}$ la libertad.

datos, para efectos de completar este artículo.

${ }^{15}$ Una de las limitantes de estos informes es que su actualización no traspasa la frontera del año 2012, a pesar de las fluctuaciones en los últimos años sobre el tema, que incluso han ameritado nuevos pronunciamientos de la Corte Constitucional al respecto.

${ }^{16}$ El término traspasa el ámbito local, con miras a describir la institución carcelaria en otros contextos. Ver Matthews (2003, p. 317 y 334).

${ }^{17}$ Fuente: Estadísticas INPEC "Población interna en Establecimientos de Reclusión y Regionales. Abril 30 de 2016"
Así, la inexistencia de cupos carcelarios que empujan al individuo privado de la libertad a ocupar los lugares destinados para el tránsito común e incluso aquellos establecidos para el aseo y la evacuación de las necesidades fisiológicas, convirtiéndolos en su zona de descanso y donde pernoctan, se fusiona con el obstáculo para acceder a los programas de resocialización (GDIP, 2010, p. 34), convirtiéndose la cárcel en un depósito de personas (Acosta, 1996, p. 90; Baratta, 1990, p. 1; Matthews, 2003, 63; Sozzo, 2007, p. 104), ${ }^{18}$ que, contrario a la idea rehabilitadora, destruye al preso y hasta a su familia (Coyle, 2005, p. 163).

Dentro del sistema progresivo contemplado en el régimen penitenciario colombiano, los programas de resocialización están ideados, no solo para que la persona privada de la libertad tenga una actividad al interior del establecimiento de reclusión y eventualmente reporte algunos beneficios económicos por el trabajo desarrollado, sino también para generar un puente hacia la vida en libertad, con la aprehensión de algún arte u oficio que le permita devengar recursos por fuera de los muros de la cárcel, desarrollando una actividad legal que lo aleje de la comisión de delitos, especialmente aquellos de contenido patrimonial. Pero, al no tener acceso a los mismos, la cárcel se convierte en un lugar apto para el ocio improductivo que, en definitiva, ratifica la idea de que el condenado, al llegar allí, se gradúa con honores, dentro de un escenario catalogado como la universidad del crimen (Sampedro, 1998, p. 109), donde el que no sabe aprende y el que sabe aprende más. ${ }^{19}$

Así, comparar el tratamiento que se le da a los presos, con el de los animales, para describir las condiciones carcelarias a las que se ven sometidos los individuos privados de

${ }^{18}$ En el mismo sentido, el Informe de la Defensoría del Pueblo "Análisis sobre el actual hacinamiento carcelario y penitenciario en Colombia” del año 2003.

${ }^{19}$ En el mismo sentido, hay la sentencia T-388 de 2013, M.P. María Victoria Calle Correa. De esta manera “... la delincuencia aparece como una solución cultural (una forma de adquirir prestigio) a un problema estructural (la falta de estatus debida a la escases de medios económicos)" (Larrauri, 2015, p. 71) 
la libertad en Colombia y en otras partes del mundo, no es tan descabellado ni irrespetuoso. En este sentido y recurriendo al contexto evidenciado en otras latitudes, algunas voces afirman que Sudáfrica trataba a los presos como animales (Mandela, 1994, p. 187). ${ }^{20}$ En nuestra jurisprudencia constitucional se advierte algo similar: "La deshumanización de las personas en los actuales contextos carcelarios es evidente. Las condiciones en que son mantenidas las personas privadas de la libertad, por ejemplo, suelen ser relacionadas con las condiciones en que existen algunos de los animales relegados en nuestra sociedad a los lugares de suciedad." Sentencia T-388 de 2013, M.P. Maria Victoria Calle Correa.

Además de las condiciones en las que viven, no deben pasarse por alto las estructuras arquitectónicas en las que aquellos son encerrados. Recordemos que las características fundamentales del panóptico de Bentham son: 1. Inspección central, 2. Minucioso dispositivo de seguridad, 3. Celda como unidad de alojamiento de varios individuos, 4. Paredes interiores formadas por una reja, que permiten la visibilidad plena y 5. Principio de clasificación moral (García, 1957, p. 594). Estas características pueden vislumbrarse en mayor o menor medida en los zoológicos y en las cárceles. Al respecto, señalaba Foucault (1976, p. 207) que

Bentham no dice si se inspiró, para su proyecto, en la casa de fieras que Le Vaux había construido en Versalles: primera colección zoológica cuyos diferentes elementos no estaban, según era tradicional, diseminados en un parque: 312 en el centro, un pabellón octogonal que, en el primer piso, sólo tenía una estancia, el salón regio; en todos los lados se abrían anchas ventanas que daban a siete jaulas (el octavo lado se reservaba a la entrada), donde estaban encerradas diferentes especies de animales.

Con lo anterior, se prioriza la seguridad sobre el tratamiento (González Sánchez, 2012, p. 368), saliendo mejor librados los semovientes en cautiverio, frente a los condenados a una

${ }^{20}$ En sentido similar, ver Crespo y Bolaños (2009, p. 69) para el caso venezolano y Matthews (2011, p. 314) en referencia a las condiciones carcelarias en Uruguay pena privativa de la libertad - por lo menos en la longitud del espacio al cual se encuentran conminados. Estos últimos, a pesar de su calidad de individuos de la especie humana, son rebajados a ese contexto.

En sentido similar, expresan Melossi y Pavarini (1987, p. 191) que la cárcel es el "parque zoológico" de todas las especies criminales y, sin duda, allí se puede encontrar un "cóctel" de internos de la más variada naturaleza (Téllez, 1996, p. 596), cuyas condiciones en la actualidad pueden ser valoradas como deplorables e infrahumanas, por lo menos dentro del ámbito nacional, rotulando este escenario como dantesco, de la misma manera que, de antaño, lo ha hecho nuestra Corte Constitucional. ${ }^{21}$

\section{Perspectiva Judicial}

La Corte Constitucional colombiana, ha declarado, en tres oportunidades, el estado de cosas inconstitucional ${ }^{22}$ en nuestras prisiones (Sentencias T-153/98, T-388/13 y T-762/15), ante la violación masiva y sistemática de los derechos fundamentales de los reclusos. Para adoptar la primera de estas providencias, se visitaron dos establecimientos carcelarios ubicados en las ciudades de Bogotá y Medellín. Allí se encontraron, entre otros hallazgos, po-

${ }^{21}$ Cfr., por todas, las sentencias T-847 de 2000, M.P. Carlos Gaviria Díaz, T-1096 de 2004, M.P. Manuel José Cepeda Espinosa y con ponencia de la Magistrada Maria Victoria Calle Correa las sentencias T-412 de 2009 y T-388 de 2013.

${ }^{22}$ Para establecer que una situación fáctica se adecúa al estado de cosas inconstitucional, la Corte Constitucional ha fijado los siguientes criterios: (i) la vulneración masiva y generalizada de varios derechos constitucionales que afecta a un número significativo de personas; (ii) la prolongada omisión de las autoridades en el cumplimiento de sus obligaciones para garantizar los derechos; (iii) la adopción de prácticas inconstitucionales, como la incorporación de la acción de tutela como parte del procedimiento para garantizar el derecho conculcado; (iv) la no expedición de medidas legislativas, administrativas o presupuestales necesarias para evitar la vulneración de los derechos; (v) la existencia de un problema social cuya solución compromete la intervención de varias entidades, requiere la adopción de un conjunto complejo y coordinado de acciones y exige un nivel de recursos que demanda un esfuerzo presupuestal adicional importante y (vi) si todas las personas afectadas por el mismo problema acudieran a la acción de tutela para obtener la protección de sus derechos, se produciría una mayor congestión judicial. Sentencia T-025 de 2004, M.P. Manuel José Cepeda Espinosa. En el mismo sentido, ver Rodríguez (2010, p. 445). 
zos de aguas negras cerca de rebosar; la sección de enfermería y sanidad se encontraba destinada parcialmente para albergar presos con perfil de máxima seguridad, percibiéndose adicionalmente malos olores; los internos habitaban túneles húmedos y oscuros, que no tienen ventilación ni luz y los baños habían sido adaptados como dormitorios. Durante la visita nocturna, se percibieron olores fétidos, poca ventilación y escasa iluminación; los internos dormían en los pasillos y en las letrinas e, incluso, las personas que adelantaron la diligencia, pisaron algunas cabezas de internos durante el transcurso de la inspección.

Con base en lo anterior, se concluyó que las condiciones en las que vivían los internos de estos establecimientos carcelarios eran inhumanas y no se compaginaban con el principio de la dignidad humana, sin que en estas condiciones se pueda cumplir en debida forma con los presupuestos establecidos para el tratamiento penitenciario. ${ }^{23}$ Adicionalmente, en el fallo de tutela, se determinó que esta situación era pregonable no solo de estos establecimientos carcelarios, sino de todos los demás que integran el sistema penitenciario y carcelario colombiano.

Se describen, adicionalmente, las falencias estructurales de la infraestructura carcelaria, ante la evidencia encontrada, que afecta tanto los servicios de acueducto y alcantarillado, como el de electricidad. Dentro de este enबं torno se constata que (i) existe hacinamiento, (ii) no hay separación de los internos por ca-

${ }^{23}$ Señala expresamente la Corte Constitucional que "las I cárceles colombianas se caracterizan por el hacinamien-

to, las graves deficiencias en materia de servicios públicos

$\wp$ y asistenciales, el imperio de la violencia, la extorsión y

la corrupción, y la carencia de oportunidades y medios

para la resocialización de los reclusos." Sentencia T-153 de 1998, M.P. Eduardo Cifuentes Muñoz. de la libertad, derechos como la vida e integridad personal, la dignidad, la igualdad, la libertad religiosa, el derecho al reconocimiento de la personalidad jurídica, a la salud y al debido proceso, y el derecho de petición, permanecen incólumes, a pesar del encierro.

La situación evidenciada en las decisiones judiciales posteriores (Sentencias T-388 de 2013 y T-762 de 2015) no varía significativamente en cuanto a la descripción fáctica, aunque se reconoce el esfuerzo realizado por el Gobierno Nacional en procura de enfrentar esta problemática, diferenciándose, por ende, la situación del año 1998 con la de los años 2013 y 2015, en que ya no existe un abandono. Confluyen las providencias citadas en afirmar que las condiciones en las que se encuentra el sistema penitenciario colombiano no permiten llevar a cabo el proceso de resocialización de los reclusos. Esto se compagina con la retribución que lleva implícita la pena y la demanda de algunos sectores de la sociedad, tendiente a que el efecto del delito sea pudrirse en la cárcel (Birckbeck, 2003, p. 44; Garland, 2005, p. 301; Gerez, 2009, p. 513; Pérez, 2012, p. 5), resultado que fácilmente podría concretarse en las condiciones en las que se encuentra el sistema penitenciario y carcelario colombiano. Sin embargo, esta no parece ser la teleología que inspira el internamiento de un penado, como quedara anotado algunas líneas más arriba.

\section{Perspectiva personal comparada}

Una vez analizadas las fuentes indirectas, hasta aquí descritas, en este punto se hará una narrativa personal, apoyada en los diarios de campo levantados como investigador, en virtud de las visitas a las cárceles colombianas y la comparación de estas con una cárcel en Cataluña. ${ }^{24}$ Lo primero que debe anotarse está relacionado con la entrada al penal y el esquema de seguridad para el acceso al mismo.

${ }^{24}$ Esto último, con ocasión de la visita realizada el día 26 de abril de 2016 al centro penitenciario Brians 1 . 
En Colombia, gracias a la colaboración de los funcionarios del INPEC, por el trabajo conjunto desplegado durante varios años, contamos con un acceso preferencial que nos evita largas filas, pero no nos exceptúa del procedimiento de reseña (que deja los dedos untados de tinta durante toda la visita), la imposición de varios sellos en los brazos (en algunas cárceles, como La Modelo de Bogotá, con tinta invisible, mientras que, en la reclusión de mujeres El Buen Pastor, nuestras extremidades terminan adornadas por animalitos que requieren de un importante tiempo de asepsia, para ser eliminados) y el cacheo superficial para evitar el ingreso de elementos prohibidos (en las cárceles La Picota de Bogotá y en El Pedregal de Medellín, se suma a este procedimiento el sometimiento ante un binomio canino para la detección olfativa de sustancias prohibidas). En contraste con lo anterior, en Brians 1, llegamos hasta los patios y las celdas sin la realización de ninguno de estos procedimientos, debiendo solamente entregar el documento de identificación a cambio de un sticker de color naranja que contiene la leyenda de "visitante" y que tuvimos que colocar en nuestro pecho.

Todas las puertas son eléctricas, similar a como funciona el sistema de seguridad en la Cárcel de alta seguridad de Combita en Boyacá, pero, en esta prisión catalana, el personal penitenciario se encuentra reducido sustancialmente y reemplazado por la tecnología. ${ }^{25}$ Otra observación importante es que, en esta cárcel, solo alojan personas condenadas. Por supuesto que en Colombia contamos con establecimientos de reclusión con esta misma destinación y los denominamos penitenciarias, ${ }^{26}$ pero, en la

${ }^{25}$ A pesar de esta información que fue suministrada por el funcionario que nos acompañó en la visita, solo logramos identificar unas cuantas cámaras de seguridad durante el recorrido.

${ }^{26}$ La diferenciación entre cárcel y penitenciaria obedece a los criterios legales consagrados en los artículos 21 y 22 del CPC. En el mismo sentido Téllez (1996, pp. 601-602 y 620 ). Mientras que la cárcel es para los sindicados, la penitenciaria es para los condenados. En este documento no se acude a la diferenciación técnica anotada y se utilizan indistintamente los términos, "cárcel", "penitenciaria", "penal" o "centro de reclusión", recurriendo de manera preponderante al primero de estos vocablos. práctica, no hemos podido lograr la separación efectiva entre condenados y sindicados, ${ }^{27}$ lo que, por contera, vulnera la presunción de inocencia de estos últimos, como se anotaba con anterioridad.

A medida que nos adentramos al corazón de Brians 1, el olfato no responde igual a como ocurre en algunas cárceles de Colombia, en donde se mezcla el olor a comida, el hedor de las aguas residuales y los humos provenientes del consumo de estupefacientes. Por supuesto que, en las prisiones españolas, hay consumo de estupefacientes, pero la amplitud de los espacios, por lo menos en este centro penitenciario en especial, no permite la concentración de los olores, a diferencia de lo que ocurre en las cárceles colombianas. Igual acontecía en algunos centros de detención de la Unión Soviética, en donde no había ventilación y casi siempre se percibían malos olores (Christie, 1993, p. 82).

Es preciso decir que Brians 1 es impecable por todos los rincones destinados para nuestro recorrido, y la sensación, en su interior, es incluso mejor que la de algunos colegios distritales en Colombia, que se encuentran abandonados. Los muros se encuentran adornados con trabajos de los reclusos y, para evitar confusiones del lector, se debe advertir que no se está haciendo referencia a grafitis. Brians 1 no padece hacinamiento. ${ }^{28}$ Las celdas se encuentran destinadas para dos (2) personas y todavía tienen cupos. Se suma a esto que cada habitación tiene televisor y baño. En las cárceles colombianas, el mismo espacio está destinado, en algunas ocasiones, para seis (6) y ocho (8) personas, e incluso algunos internos deben pernoctar en los corredores (lo que ellos llaman dormir en carretera) y los más desafortunados son empujados a los baños, donde en vez de un osito de felpa, comparten la noche

27 En otras cárceles de España, acontece igual (González Sánchez, 2012, p. 391).

${ }^{28}$ En otras cárceles españolas, ciertamente existe sobreocupación (González Sánchez, 2012, pp. 367-368) 
con roedores. ${ }^{29}$ Los baños son comunales y hay un televisor en el patio.

Siguiendo con la misma temática de los cupos carcelarios, en las cárceles colombianas es inevitable ver brazos y piernas colgando de los barrotes, como si se tratara de un bazar de carne humana ${ }^{30}$ No ocurre lo mismo en este centro penitenciario que adicionalmente cuenta con dos canchas de baloncesto dentro de un módulo (patio) y otros espacios comunes, que en las cárceles colombianas no alcanzan a la mitad de esta longitud. Como si esto fuera poco, cuentan con un polideportivo dotado, en debida forma, para realizar prácticas deportivas. Dentro de la visita incluso nos comentan que, en el centro penitenciario aledaño (Brians2), hay piscina, pero que, por la crisis económica, debió ser cerrada. Esto no impide que muchos condenados se presenten voluntariamente a estos establecimientos, con miras a purgar su pena al interior de los mismos, en virtud de las buenas condiciones que presentan.

Adicionalmente, los reclusos en este establecimiento español cuentan con unas habitaciones cómodas para la visita conyugal, entregándoles un juego de sabanas y preservativos; mientras que, en el contexto colombiano, los reclusos deben turnarse la celda para que cada uno de ellos pueda estar con su pareja, sin ninguna especie de profilaxis en los tendidos ثิ que utilizan. En Brians 1 también existen unos ه cuartos que tienen la estructura de una sala

${ }^{29}$ En algunas cárceles de Estados Unidos, las condiciones también son deplorables de antaño: "La pintura de las paredes está descascarada; hay filtraciones de agua, los vidrios

de las ventanas están rotos; no hay suficiente luz, hay cuca-

rachas, ratas, ratones, hormigas y mosquitos; las almohadas

y los colchones están sucios y mohosos, y no tienen funda

de plástico; el calor en verano es insoportable y el frio en invierno es muy intenso" (Christie, 1993, p. 97).

${ }^{30}$ La metáfora es de Foucault (1976, p. 261).
Colombia, deben interponer acciones de tutela (recurso de amparo) para que les garanticen el suministro de agua. ${ }^{31}$

Al final de la visita, nos llevaron a donde inicia el tratamiento penitenciario, que, en el ámbito colombiano, correspondería a la fase de observación. Para esto están destinadas unas celdas especiales en donde aguardan la visita del médico que diagnosticará su estado de salud. Aunque este mandato está consagrado en la legislación colombiana, muchas veces no se cumple, y la fase de observación se extiende por meses, mientras que en Brians 1, exageradamente, puede alcanzar los 5 días.

Seguramente si comparamos Brians 1 con las prisiones nórdicas, ${ }^{32}$ la experiencia igualmente resultará asombrosa, o incluso, si no se conoce ninguna cárcel, entrar a esta prisión catalana por primera vez, termina siendo impactante. En todo caso, esta perspectiva comparada sirve para la reflexión sobre la funcionalidad de la cárcel en el contexto colombiano, dentro de un ambiente denigrante que imposibilita la resocialización.

\section{INGRESO A LA PRISIÓN Y TRA- TAMIENTO PENITENCIARIO EN COLOMBIA}

Desde la llegada del interno al establecimiento de reclusión, comienza el tratamiento penitenciario, con la fase de observación y diagnóstico, que implica verificar la validez de la orden judicial emitida, la cual debe venir acompañada con su identificación (plena identidad), ${ }^{33}$ procediendo a la reseña del sujeto

${ }^{31}$ En el mismo orden, en algunas cárceles españolas, el agua no es potable (González Sánchez, 2012, p. 356).

${ }^{32}$ Para citar un ejemplo, en Noruega, las celdas son individuales (Christie, 1993, pp. 44-45).

${ }^{33}$ Una vez realizada la captura, se deben confrontar las huellas dactilares del individuo con el archivo existente en la Registraduría Nacional del Estado Civil, con miras a disipar cualquier duda sobre su identidad y la eventual existencia de homónimos o exhibición de documentos falsos (lo que se conoce en el argot carcelario como "chapas”), razón por la cual dicha comparación va más allá del simple cotejo de un documento de identidad. 
(identificación decadactilar, alfabética, biográfica, morfológica y fotográfica). ${ }^{34}$ Culminado lo anterior, se hace el registro del individuo en el Sistema de Información de Sistematización Integral del Sistema Penitenciario y Carcelario (en adelante SISIPEC ${ }^{35}$ ) y tras ser requisado, se le retiran todos los objetos personales, los cuales serán entregados a quien el individuo manifieste o depositados donde señale el reglamento interno. En caso de ser depositados, se expide un recibo que será entregado a la persona privada de la libertad. ${ }^{36}$ Concluido lo anterior, se realiza un examen médico para verificar su estado físico, las patologías y demás afecciones. ${ }^{37}$ Con base en esto, se elabora la ficha médica correspondiente.

Al interno se le debe suministrar la información apropiada sobre el régimen del establecimiento de reclusión al que está ingresando (derechos, deberes, normas disciplinarias, procedimientos para formular quejas y reclamaciones),${ }^{38}$ haciéndole entrega de un ejemplar impreso del reglamento disciplinario interno. ${ }^{39}$ Igualmente se debe garantizar que, a la mayor brevedad posible, la persona privada de la libertad cuente con la oportunidad de comunicar a sus familiares donde se encuentra.

Superado lo anterior, el interno es alojado al interior del sitio de reclusión y, muy a pesar del pensamiento lógico acerca de que, en la prisión, se restringen al máximo las actividades de los individuos, sometidos al control del Estado bajo la privación de la libertad, la

${ }^{34}$ De conformidad con lo establecido en el artículo 56 del CPC
${ }^{35}$ De acuerdo con la Resolución 3670 de 2011 (INPEC), el
aplicativo misional SISIPEC se adopta como única fuente
de información. La calidad de la información recae en ca-
beza de los directores de los establecimientos.
${ }^{36}$ De conformidad con lo establecido en el artículo 60 del
CPC. De manera similar ocurre en el sistema penitenciario
español (Albinyana y Cervera, 2014, pp. 122-123).
${ }^{37}$ Esto se encuentra regulado en el artículo 61 del CPC y
guarda correspondencia con los lineamientos establecidos
por el principio 24 del Conjunto de Principios para la pro-
tección de todas las personas sometidas a cualquier forma
de detención o prisión, adoptado por la Asamblea General
de la Organización de Naciones Unidas (ONU) en su reso-
lución 43/173, de 9 de diciembre de 1988 .
${ }^{38}$ Cfr. Artículo 58 CPC
${ }^{39}$ Sentencia T-793/08, M.P.: Humberto Antonio Sierra Porto. realidad muestra que el manejo del poder se encuentra radicado en cabeza de determinados grupos que imponen sus reglas y coordinan el funcionamiento del establecimiento (Garcia-Pablos de Molina, 1988, p. 41; García-Borés, 2003, p. 389), debiendo el interno adaptarse a esta subcultura carcelaria (Crewe, 2012, pp. 32-38; Echeverri, 2010, p. 158, Matthews, 2003, p. 82-90). ${ }^{40}$

Ahondando sobre este tema, ${ }^{41}$ Sykes y Messenger (1960, p. 5) advierten que: "a pesar del número y diversidad de la población reclusa, se observa que tales grupos poseen un sorprendente y compenetrado sistema de valores. Este sistema de valores de los prisioneros comúnmente toma la forma de un explícito código, cuyas breves normas sirven de guía y control para la conducta de los internos en su relación con otros internos y con los custodios."

Ahora bien, el sistema penitenciario colombiano es de carácter progresivo (Acosta, 1996, p. 45-46; Rueda, 2010, p. 73; Téllez, 1996, p. 621) y el tratamiento que se brinda a la persona privada de la libertad busca prepararla para que, en el futuro, viva en paz con los demás miembros de la sociedad, ${ }^{42}$ respetando los bienes jurídicos protegidos por el legislador. Pregonar que nuestro país tiene un sistema progresivo demanda el cumplimiento de tres características, en especial (Guillamondegui, 2010, p. 42):

1. División del tiempo de la sanción penal en partes con un contenido propio y diferente en alguno de sus elementos;

2. Avance o retroceso del sentenciado durante esas etapas, grados o periodos mediante una valoración actualizada e individual del condenado;

40 "La ausencia de un sentido del deber entre los reclusos, la falacia de la coerción, la patética colección de recompensas o castigos para inducir la complicidad, las presiones para corromper al guardia disfrazadas de amistad, reciprocidad y transferencia de obligaciones institucionales a los reclusos de confianza son más bien defectos estructurales del sistema de poder de la prisión que problemas individuales" (Sykes, 1997, p. 61).

${ }^{41}$ Ver también Clemmer (1958)

${ }^{42}$ En sentido similar, ver sentencias T-1670 de 2000, M.P. Carlos Gaviria Díaz, T-213 de 2011, M.P. Gabriel Eduardo Mendoza Martelo 
3. Posibilidad de la incorporación social del condenado antes del agotamiento del tiempo fijado para la pena en la sentencia. ${ }^{43}$

Cuadro 1 - Fases de tratamiento penitenciario y características

\begin{tabular}{|l|l|}
\hline FASES DE TRATAMIENTO & \multicolumn{1}{|c|}{ CARACTERísTICAS } \\
\hline $\begin{array}{l}\text { Observación, diagnóstico y } \\
\text { clasificación del interno }\end{array}$ & $\begin{array}{l}\text { Esta primera fase inicia desde el momento en que el condenado llega a la prisión y se } \\
\text { realiza el proceso de identificación y registro, determinándose su lugar de reclusión } \\
\text { al interior de la penitenciaria (distribución interna), así como los programas reque- } \\
\text { ridos para desarrollar su proceso resocializador. Para este efecto, se tienen en cuenta } \\
\text { tanto la naturaleza del delito por el cual fue condenado, como su edad, género, per- } \\
\text { sonalidad y su perfil criminológico, en lo que atiende a criterios de reincidencia. }{ }^{44} \\
\text { La duración de esta fase está comprendida entre uno y 3 meses }\end{array}$ \\
\hline Alta seguridad & $\begin{array}{l}\text { Comprende el período cerrado de reclusión. }{ }^{46} \text { Desde esta fase se deben desarrollar } \\
\text { actividades de resocialización. }\end{array}$ \\
\hline Mediana seguridad & $\begin{array}{l}\text { Comprende el período semiabierto. Para acceder a esta fase, se deben haber desar- } \\
\text { rollado actividades de resocialización de manera exitosa, así como haber observado } \\
\text { buen comportamiento durante el tiempo de privación de la libertad, que debe supe- } \\
\text { rar la tercera parte de la pena. La característica fundamental del período semiabierto } \\
\text { radica en la posibilidad de obtener permisos de salida del establecimiento de reclu- } \\
\text { sión, hasta por 72 horas }\end{array}$ \\
\hline Mínima seguridad & $\begin{array}{l}\text { Es el período abierto. Se deben haber superado las 4/5 partes de la pena. En esta } \\
\text { fase, se amplía la baraja de permisos a los cuales puede hacerse acreedor el interno, } \\
\text { pudiendo salir del establecimiento de reclusión por períodos que comprenden el fin } \\
\text { de semana e incluso alcanzan los } 15 \text { días. }\end{array}$ \\
\hline De confianza & $\begin{array}{l}\text { Coincidirá con la libertad condicional. Es decir, que se ha superado el requisito } \\
\text { objetivo para acceder a este subrogado (3/5 partes de la pena), pero el mismo pudo } \\
\text { ser negado por otras circunstancias. }{ }^{47} \text { En esta fase, el interno puede acceder a los } \\
\text { beneficios de libertad y franquicia preparatoria. }{ }^{48}\end{array}$ \\
\hline
\end{tabular}

Fuente: Elaboración propia con base en el artículo 153 del CPC.

${ }^{43}$ De antaño, señalaba Dorado (1915, p. 305) que una de las particularidades de esta clase de sistema es poder reducir la duración de las condenas.

${ }^{44}$ Cfr. Artículo 63 CPC.

${ }^{45}$ Artículo 10, Resolución 7302 de 2005 (INPEC).

${ }^{46}$ De conformidad con el artículo 10 de la Resolución No 7302 de 2005, deberán permanecer en fase de Alta Seguridad "aquellos internos(as) que presenten algunas de las si$\wedge$ guientes situaciones. Desde el factor objetivo: 1. Condena

$\checkmark \vec{\sigma}$ por delitos que el legislador excluye de manera taxativa.

2. Presenten requerimientos por autoridad judicial. 3. Pre$\dot{\sim}$ senten notificación de nueva condena. 4. No hayan cum-

Q plido con una tercera parte (1/3) de la pena impuesta, en el

E caso de justicia ordinaria o del $70 \%$ de la pena impuesta en

$\infty$ el caso de justicia especializada. 5. Registren acta de segu-

of ridad que restrinja su movilidad para evitar atentados con-

L 10 tra la vida e integridad de otras personas o de sus bienes.

'́ Desde el factor subjetivo: 1 . Presenten elevados niveles de

iD violencia. 2. No asuman normas que permitan la convi-

$\dot{2}$ vencia en comunidad. 3. Sean insensibles moralmente y

$\therefore$ presenten trastornos severos de personalidad. 4. No hayan

$\infty$ participado, de manera activa y responsable, en el Sistema

\& de Oportunidades. 5. Por concepto del psiquiatra, deban

\& recibir atención y tratamiento especializado dadas las li-

$\%$ mitaciones de su estado de salud mental. 6. Aquellos in-

$>$ ternos que, a juicio de la Junta de Distribución de Patios y

ô asignación de celdas, deban estar recluidos en lugares de

Z alta seguridad conforme al parágrafo del artículo 17 del

Acuerdo 0011 de 1995, con tratamiento especial."

क ${ }^{47}$ Algunos de los factores por los cuales puede resultar neI gada la libertad condicional es por no adjuntarse todos los documentos requeridos para este efecto, por la gravedad

de la conducta y por el mal comportamiento en el estable-

cimiento de reclusión. Para un estudio empírico al respec-

to, ver Hernández (2015).

डै ${ }^{48}$ Cfr. Artículo 144 CPC.
Estas características se consagran en abstracto dentro de las fases de tratamiento, en donde se modula el programa de resocialización, junto con las actividades que se desarrollan dentro de las mismas y los permisos a los que puede acceder el interno, dependiendo de esta clasificación. Así, el sistema penitenciario colombiano consagra las fases indicadas en el Cuadro n. 1.

Como regla general para el ascenso entre fases, se debe haber observado una buena conducta durante el tiempo de reclusión así como acreditar la participación en actividades de resocialización. En las primeras tres fases, son obligatorios los programas de educación penitenciaria encaminados a la resocialización del interno, sin que se excluya el trabajo, que adicionalmente es considerado como obligatorio. ${ }^{49}$ Estos programas son impartidos bajo la misma teleología resocializadora ${ }^{50}$ y se exceptúan de obligación de laborar a las personas mayores de 60 años, las mujeres durante los 3 meses anteriores al parto y el mes siguiente

${ }^{49}$ Lo mismo ocurre en el sistema penitenciario español (Albinyana; Cervera, 2014, p. 264).

50 En este sentido, ver sentencias T-601 de 1992, M.P. Eduardo Cifuentes Muñoz, C-394 de 1995, M.P. Vladimiro Naranjo Mesa, T-1093 de 2005, M.P. Clara Inés Vargas Hernández, T-429 de 2010, M.P. Juan Carlos Henao Pérez y T-286 de 2011, M.P. Jorge Ignacio Pretelt Chaljub. 
al mismo y quienes padezcan una enfermedad que les imposibilite la realización de alguna actividad laboral. ${ }^{51}$ Como se observa en el Cuadro 1, la clasificación, en estas fases, es importante para efectos de acceder a beneficios y permisos administrativos, ${ }^{52}$ siendo competencia del Consejo de Evaluación y Tratamiento (en adelante CET) de cada establecimiento de reclusión la decisión de promover al interno, en las distintas fases del sistema progresivo, lo cual, en muchas oportunidades, se demora hasta un año y le imposibilita al interno gozar de los beneficios, a pesar de cumplir con los requisitos para este efecto (Colombia, 2014, p. 44, 89, 111, 113).

\section{LA RESOCIALIZACIÓN DEL CON- DENADO EN COLOMBIA}

De conformidad con lo señalado por el organismo que administra el sistema penitenciario y carcelario colombiano, la resocialización es una "técnica de tratamiento clínico que pretende cambiar la conducta del interno. Volver a socializarse, lo que significa aprender las expectativas sociales e interiorizar normas de conducta. Resocializarse es volver a valer como ser social conforme quiere la sociedad. Esto implica reconocimiento. La técnica que se maneja es el cambio de actitud y de valores. Se confunde con el cambio de delincuente en un buen interno(a)." (Colombia, 2016, p. 11). ${ }^{53}$

A continuación, se señalan los elementos fundamentales que hacen parte de la idea ${ }^{51}$ Cfr. Artículo 83 CPC. Tampoco es obligatorio para quieT-429 de 2010, M.P. Juan Carlos Henao Pérez)

${ }^{52}$ Muchas veces, estos beneficios no son tramitados por los establecimientos de reclusión (Ministerio de Justicia y del Derecho, 2014, p. 91), lo que imposibilita su contacto con el exterior.

${ }^{53}$ En sentido similar, ver Acosta (1996, p. 147). Muñoz Conde (1982, p. 138) considera que "la resocialización debe consistir en hacer aceptar al delincuente las normas básicas y generalmente vinculantes que rigen una sociedad. Una parte importante, aunque no exclusiva, de esas normas está formada por las normas penales, así que el objetivo de la resocialización sería el respeto y la aceptación por parte del delincuente de las normas penales, con el fin de impedirle cometer en el futuro nuevos delitos”. de resocialización dentro del tratamiento penitenciario colombiano.

1. Es un tratamiento que se brinda al condenado tras la sentencia de responsabilidad penal;

2. Este tratamiento le permitirá retornar a la sociedad con el conocimiento del actuar errado y la concientización por el respeto a las normas establecidas por la sociedad;

3. El tratamiento genera un bloqueo frente a la comisión de nuevos delitos en el futuro. ${ }^{54}$

De manera operativa, este proceso se obtiene a través del trabajo, ${ }^{55}$ el estudio, la disciplina, la instrucción, la cultura, el deporte, la recreación y las relaciones de familia (Colombia, 2015, p. 55). ${ }^{56}$ Asimismo, para preparar al individuo hacia el tránsito a la vida en libertad, se le deben ofrecer opciones de contacto con la sociedad extramuros, por lo que adquieren importancia los diferentes permisos y beneficios penitenciarios, que le permiten salir de la prisión con anterioridad al cumplimiento de la pena (Rueda, 2010, p. 138). Se desprende de lo anterior que básicamente son tres las actividades que desempeñan los internos dentro de los programas de resocialización, que, a su vez, les permiten redimir pena por trabajo, estudio y enseñanza. ${ }^{57}$ Pero incluso señala la legislación penitenciaria, que se puede redimir pena por actividades literarias, deportivas, artísticas y en comités de internos, las cuales se asimilan al estudio. ${ }^{58}$

En este sentido, se debe advertir que la

${ }^{54}$ Es un proceso que elimina los incentivos para la comisión de actividades ilegales (Dejong, 1997, p. 561).

55 “... el trabajo ha sido históricamente el hecho central del encarcelamiento; oscilando, por una parte, entre las formas productivas y comercializadas de la industria, y las estrategias de capacitación y rehabilitación, por la otra" (Matthews, 2003, p. 71)

56 Sobre este aspecto en particular, ver las sentencias T-274/05, T- 1275/05 y T-572/09, M.P. Humberto Antonio Sierra Porto.

${ }^{57}$ En el mismo sentido, ver el documento CONPES 3828 (2015, p. 44). Los documentos CONPES son elaborados por el Consejo Nacional de Política Económica y Social de Colombia y se encargan de planear todos los aspectos relacionados con el desarrollo económico y social del país. El documento CONPES citado trata sobre la política penitenciaria y carcelaria en Colombia.

${ }^{58}$ Cfr. Artículo 99 CPC. 
redención de pena no es un beneficio ni un subrogado (mecanismo sustitutivo de la pena), sino una expresión de la dignidad humana y un instrumento por medio del cual el Estado ofrece al penado la posibilidad de resocializarse. Además de percibirse una remuneración ${ }^{59}$ como contraprestación por el trabajo realizado, esta clase de actividades repercuten en el descuento del tiempo impuesto como pena privativa de la libertad. Desde esta perspectiva, resulta interesante detenerse brevemente en el análisis de las prohibiciones consagradas por el Código de la Infancia y la Adolescencia (Ley 1098 de 2006) para sujetos condenados por determinados delitos cometidos en contra de personas menores de 14 años. Esta norma consagra que, en esta clase de delitos, no procede ningún beneficio, ni subrogado judicial o administrativo. No obstante lo anterior, esta restricción no es aplicable para la redención de pena como derecho que tiene el condenado (Sentencia T-718/15, M.P. Jorge Iván Palacio). En el mismo sentido lo ha señalado la Corte Suprema de Justicia (Sala Penal), en sentencia del 2 de julio de 2015 [STP-8442 (80488)], ${ }^{60}$ considerando la redención de pena como un derecho a partir de la interpretación de la reforma contenida en el artículo 64 de la Ley 1709 de $2014 .{ }^{61}$

Tabla 1 - Actividades de redención de pena, descuentos e intensidad horaria

\begin{tabular}{l|l|l}
\hline REDENCIÓN & DESCUENTO & INTENSIDAD \\
\hline
\end{tabular}

\begin{tabular}{l|c|c}
\hline \multirow{\infty}{*}{ DE PENA } & PUNITIVO & HORARIA \\
\hline
\end{tabular}

\begin{tabular}{|c|c|c|}
\hline Trabajo & $2 \times 1$ & 8 horas $=1$ día \\
\hline Estudio & $2 \times 1$ & 6 horas $=1$ día \\
\hline
\end{tabular}

$\stackrel{i}{i}$

¿59 Esta remuneración, que, a voces del artículo 86 CPC, debe ser equitativa, no necesariamente corresponde al salario mínimo legal, a menos que se trabaje con un tercero que haya contratado con el establecimiento de reclusión,

i caso en el cual las condiciones deben ser similares a las

I que existen para el trabajo libre (Sentencia T-429 de 2010, M.P. Juan Carlos Henao Pérez).

${ }^{60}$ M. P. José Luis Barceló Camacho.

${ }^{61}$ En el mismo sentido, ver el informe del Ministerio de Justicia y del Derecho (2014, p. 38).
En la Tabla anterior se puede observar que las tres modalidades con las que se puede optar por la redención de pena exigen la realización de la actividad durante dos días, a cambio de un día de pena privativa de la libertad. La diferencia radica en el tiempo contabilizado para efectos de acreditar los dos días de trabajo, estudio y enseñanza, ya que, en el primer caso, se deberán emplear 16 horas, mientras que, en el segundo, 12 horas y, en el tercero, 8 horas, resultando más benéfico enseñar que trabajar con el objetivo de descontar pena. Sin embargo, esta última actividad no reporta beneficios económicos en calidad de remuneración, como si lo hace la primera. Uno de los problemas que se presenta para el reconocimiento de esta redención de pena es que la competencia se encuentra atribuida a los Juzgados de Ejecución de Penas y Medidas de Seguridad, cuyo trámite suele ser demorado (Colombia, 2014, p. 89).

En la Tabla 2, se observan los datos relacionados con las personas privadas de la libertad que han podido participar de estas actividades, que además de contribuir a su proceso de resocialización, les reportan beneficios relacionados con el descuento del tiempo efectivo de pena privativa de la libertad que deben pagar, pudiendo también acceder a permisos de salida en virtud de esta reducción e, incluso, obteniendo una remuneración, que, aunque incipiente, puede ser de utilidad para su subsistencia en prisión o la colaboración con las necesidades que demandan sus hogares.

El INPEC afirma que, para marzo de 2016, el 48.6\% (44.744) de la población interna realizó trabajos en las áreas industrial, artesanal, agropecuaria y de servicios administrativos (al interior de los establecimientos de reclusión, ejecutando actividades orientadas al embellecimiento y mantenimiento del establecimiento), 49,4\% (45.559) asistió a los programas educativos, "construyendo la base fundamental para su resocialización” y el 2.0\% (1.843) se desempeñó como instructor dentro del establecimiento. Concluye que el 75.5\% de 
Tabla 2 - Población de internos ocupados en trabajo, estudio y enseñanza por generación - (Abril 30 de 2016)

\begin{tabular}{l|c|c|c|c|c|c|c|c|c}
\hline \multirow{2}{*}{ REGIONALES $^{62}$} & \multicolumn{2}{|c|}{ TRABAJO } & \multicolumn{2}{c|}{ ESTUDIO } & \multicolumn{2}{c|}{ ENSENANZA } & \multirow{2}{*}{$\begin{array}{c}\text { TOTAL } \\
\text { Hombres }\end{array}$} & $\begin{array}{l}\text { TOTAL } \\
\text { Mujeres }\end{array}$ & \multirow{2}{*}{ TOTAL } \\
\cline { 2 - 10 } & Hombres & Mujeres & Hombres & Mujeres & Hombres & Mujeres & & \\
\hline Central & 14749 & 983 & 16068 & 1002 & 700 & 44 & 31517 & 2029 & 33546 \\
\hline Occidente & 7588 & 720 & 7525 & 750 & 283 & 30 & 15366 & 1500 & 16866 \\
\hline Norte & 4865 & 283 & 4167 & 124 & 182 & 13 & 9214 & 420 & 9634 \\
\hline Oriente & 5429 & 498 & 4067 & 267 & 164 & 24 & 9660 & 789 & 10449 \\
\hline Noroeste & 3640 & 483 & 5277 & 520 & 150 & 16 & 9067 & 1019 & 10086 \\
\hline Viejo Caldas & 5500 & 522 & 5031 & 591 & 204 & 35 & 10735 & 1178 & 11913 \\
\hline TOTAL & $\mathbf{4 1 7 4 1}$ & $\mathbf{3 5 1 9}$ & $\mathbf{4 2 1 3 5}$ & $\mathbf{3 2 5 4}$ & $\mathbf{1 6 8 3}$ & $\mathbf{1 6 2}$ & $\mathbf{8 5 5 5 9}$ & $\mathbf{6 9 3 5}$ & $\mathbf{9 2 4 9 4}$ \\
\hline
\end{tabular}

Fuente: SISIPEC WEB. INPEC, Estadísticas Abril de 2016.

la población interna participó de estos programas de resocialización (INPEC, 2016, p. 41). En todo caso, estas cifras pueden ser inexactas, ${ }^{63}$ ya que no se distingue entre los reclusos que realizan más de una actividad, es decir, que estudian un día y trabajan otro, siendo tabulada esta información sin discriminar la duplicidad, lo que puede terminar afectando el monto global.

Adicionalmente y aceptando el porcentaje de internos que participaron en programas de resocialización, que supera las tres cuartas partes (3/4) de la población reclusa, esta actividad continúa sin beneficiar a la totalidad de los internos, como se describía desde el informe sombra presentado al CDH de las Naciones Unidas en respuesta al sexto informe de Colombia (GDIP, 2010, p. 32), a pesar de que, en la actualidad, se evidencia cierta mejoría. No obstante, los datos estadísticos no brindan información cualitativa que si es recogida en el informe sombra relacionado, con base en entrevistas realizadas a funcionarios del INPEC, donde se señala que los programas no son adecuados y existe carencia de personal docente capacitado para el ejercicio de esta labor, que, en últimas, es suplida por los propios internos (GDIP, 2010, p. 32). La misma situación se replica frente a las demás actividades. El

${ }^{62}$ El INPEC agrupó los establecimientos carcelarios en función de la zona en la que se encuentran situados dentro del territorio nacional.

63 "Las estadísticas carcelarias están sujetas a problemas de exactitud en la obtención de datos [...] esto puede afectar la calidad de los datos" (Matthews, 2003, p. 135). mismo Ministerio de Justicia y del Derecho (2014, p. 77) advierte sobre la carencia de formación especializada de los funcionarios que intervienen en el tratamiento penitenciario y la carencia de fundamentación sobre el tópico de la resocialización. En este último informe, también se consagran datos cualitativos, fruto de las visitas realizadas a los establecimientos de reclusión, evidenciando que, en estos, existen altos niveles de desocupación por parte de los internos. Se suma a esto la carencia de elementos para llevar a cabo tanto las actividades laborales como las educativas (Colombia, 2014, p. 80).

En el mismo sentido, la Defensoría del Pueblo indica que "la incapacidad resocializadora del estado colombiano adquiere mayor dimensión al observar el parágrafo del artículo 144 del Código Penitenciario y Carcelario, el cual supedita el fin principal de la pena privativa de libertad a las disponibilidades del personal y de la infraestructura de los centros de reclusión, lo que no se cumple en la actualidad". ${ }^{64}$ En virtud de lo anterior, la Corte Constitucional concluye que "el Sistema Carcelario actual no dispone de parámetros comunes y claros sobre los programas de resocialización, como consecuencia del abandono que ha tenido la reinserción social de quien ha cometido un delito, en la Política Criminal." (Sentencia T-762 de 2015).

Esta situación no es novedosa si anali-

${ }^{64}$ Informe del 22 de junio de 2015, citado en la sentencia T-762 de 2015, M.P. Gloria Stella Ortíz Delgado. 
zamos el informe del Alto Comisionado de las Naciones Unidas para los Derechos Humanos (2001, p. 79), en donde se establece que el sistema penitenciario colombiano no cumple con el fin resocializador, en la medida que existen altos índices de reincidencia y altos niveles de violencia carcelaria, así como drogadicción y proliferación de bandas criminales al interior de los muros, lo que, a su vez, propicia y favorece la corrupción y la victimización de la población recluida. Varios de estos aspectos permanecen estables, como se expone en el informe del Ministerio de Justicia y del Derecho (2014, p. 77).

Adicionalmente, el documento CONPES 3828 (Colombia, 2015, p. 8) reitera que la infraestructura es insuficiente para la implementación del programa de resocialización y que esto no es un problema reciente sino de varios años atrás, lo que se ratifica en el tiempo, con el estudio de la sentencia T-153 de 1998 y el informe de la ONU anteriormente relacionado y los documentos más recientes analizados. A su vez, el mismo documento (COLOMBIA. 2015, p. 46), con base en el informe del Ministerio de Justicia y del Derecho (2014), señala las siguientes falencias:

- Las actividades de tratamiento penitenciario para la resocialización no tienen enfoque productivo y competitivo;

亏ิ . Se cuenta con escasa participación privada;

. Existen debilidades en la articulación del modelo educativo para la población privada de la libertad con las políticas de educación nacional;

- Hay una capacidad limitada para la implementación del modelo educativo para la población privada de la libertad;

. Existe una baja interacción con los ámbitos familiar, comunitario y social en los programas de atención social y tratamiento penitenciario;

- Se presentan debilidades en los procesos de evaluación y tratamiento a la población privada de la libertad.

Tanto el informe del Ministerio de Jus- ticia y del Derecho (2014, p. 79), como el documento CONPES y la sentencia T-762, estos últimos del año 2015, muestran un panorama desfavorable en materia de resocialización al interior de los establecimientos de reclusión del país, poniendo en jaque el cumplimiento de esta función, ante la ausencia de una infraestructura apta para la consecución de este fin, la carencia de personal capacitado para el desarrollo de los programas y la poca efectividad de los mismos.

Por otra parte y con base en los elementos inicialmente señalados dentro de este acápite, que hacen parte de la idea de resocialización, deberá evaluarse el fenómeno de la reincidencia como factor fundamental de este proceso. ${ }^{65}$ En la siguiente Tabla se observa la tasa de reincidencia de la población reclusa en Colombia.

Con base en la información tabulada y teniendo presente que la población privada de la libertad, para abril de 2016, alcanza el número de $122.016,{ }^{66}$ se puede afirmar que más del 14\% de la población interna en Colombia es reincidente. Es decir que, a pesar de haber ingresado con anterioridad a un establecimiento de reclusión y recibir el tratamiento contemplado dentro del sistema progresivo penitenciario, este no funcionó, por lo menos en lo que atiene al objetivo de bloquear la futura comisión de delitos.

Aunque esta cifra no parece tan alarmante, siendo cautelosos con la información que arrojan estas estadísticas, es preciso advertir que, en un informe del año 1989 del Ministerio de Justicia y del Derecho, en el que se empleó una encuesta para establecer el índice de reincidencia, se anota que el $27,067 \%$ de la población condenada se encuentra en esta situación; sin embargo, el 35\% de los condenados no respondió la encuesta. Esto permite reflexionar seriamente en retrospectiva, ya que

${ }^{65}$ Las tasas de reincidencia también se presentan como evidencia de que la cárcel no cumple como un eficiente disuasivo específico (Matthews, 2003, p. 140).

${ }^{66}$ Fuente: Estadísticas INPEC "Población interna en Establecimientos de Reclusión y Regionales. Abril 30 de 2016 ” 
Tabla 3 - Reincidencia Población de internos (Abril 30 de 2016)

\begin{tabular}{|c|c|c|c|c|c|c|c|c|c|c|}
\hline \multirow{2}{*}{ REGIONALES } & \multicolumn{2}{|c|}{ ALTAS } & \multirow{2}{*}{$\begin{array}{l}\text { TOTAL } \\
\text { ALTAS }\end{array}$} & \multicolumn{2}{|c|}{ DOMICILIARIAS } & \multirow{2}{*}{$\begin{array}{c}\text { TOTAL } \\
\text { DOMICI- } \\
\text { LIARIAS } \\
\end{array}$} & \multicolumn{2}{|c|}{$\begin{array}{c}\text { VIGILANCIA ELEC- } \\
\text { TRÓNICA }\end{array}$} & \multirow{2}{*}{$\begin{array}{c}\text { TOTAL VIGI- } \\
\text { LANCIA ELEC- } \\
\text { TRÓNICA } \\
\end{array}$} & \multirow{2}{*}{$\begin{array}{c}\text { TOTAL } \\
\text { GENERAL }\end{array}$} \\
\hline & Hombres & Mujeres & & Hombres & Mujeres & & Hombres & Mujeres & & \\
\hline Central & 4971 & 342 & 5313 & 726 & 115 & 841 & 200 & 19 & 219 & 6373 \\
\hline Occidente & 2476 & 170 & 2646 & 424 & 69 & 493 & 42 & 3 & 45 & 3184 \\
\hline Norte & 1068 & 19 & 1087 & 323 & 44 & 367 & 38 & 3 & 41 & 1495 \\
\hline Oriente & 1270 & 65 & 1335 & 239 & 30 & 269 & 15 & 7 & 22 & 1626 \\
\hline Noroeste & 1819 & 121 & 1940 & 413 & 47 & 460 & 79 & 0 & 79 & 2479 \\
\hline Viejo Caldas & 1881 & 145 & 2020 & 300 & 72 & 372 & 71 & 2 & 73 & 2471 \\
\hline TOTAL & 13485 & 862 & 13347 & 2425 & 377 & 2802 & 445 & 34 & 479 & 17628 \\
\hline
\end{tabular}

Fuente: SISIPEC WEB. INPEC, Estadísticas Abril de 2016.

resulta dudoso que, con el paso de los años, hasta la fecha, se haya logrado bajar más de 10 puntos porcentuales la ocurrencia de este fenómeno, a lo que se suma la cifra negra registrada, que también puede existir en la actualidad. Esto último, atendiendo a que los datos contenidos en la Tabla 3 son elaborados con base en el aplicativo SISIPEC, el cual solo fue implementado hasta enero de 2009. Por esta razón, los índices de reincidencia ofrecidos por el INPEC no arrojan una información certera sobre el fenómeno de la reincidencia respecto de personas que hayan sido privadas de la libertad antes del año 2009 y nuevamente se hayan encontrado en esta situación con posterioridad a esta fecha límite.

La Defensoría del Pueblo ha conceptuado sobre la fiabilidad de la información suministrada por el INPEC para evaluar conceptos como número de personas recluidas, rangos de edad, actividades de resocialización desarrolladas, entre otros. Sin embargo, no son fiables en lo concerniente con la capacidad real de los establecimientos. ${ }^{67}$ Respecto a la reincidencia, aunque la Corte Constitucional, en la sentencia T-762 de 2015, no hace ninguna observación sobre la fiabilidad de los datos aportados por el INPEC, si advierte sobre la necesidad de crear un sistema donde quede señalada esta situación, junto con sus causas, con miras a identificar los problemas del proceso de resocialización. Es decir, que se carece de información certera y además que el cumplimiento

${ }^{67}$ Informe del 22 de junio de 2008, citado en la sentencia T-762 de 2015, M.P. Gloria Stella Ortíz Delgado. de esta función no ha sido satisfecho, siendo uno de los factores que conllevan a pregonar el estado de cosas inconstitucional en las prisiones del país.

\section{CONCLUSIONES}

Las legislaciones contemporáneas tienden a consagrar una miscelánea de fines de la pena ${ }^{68}$ dentro de los cuales se encuentra la resocialización, que opera fundamentalmente durante la fase de ejecución de la misma (Bacigalupo, 1978, p. 16, apud Luzón, 1979, p. 21). Esta teoría polifuncional, ${ }^{69}$ con mayor acento en la reeducación (Baratta, 1989, p. 202), se edifica sobre la intención de que la pena corrija al delincuente (Lastres, 1887, p. 114). A pesar de lo anterior, esta teleología suele quedarse en el discurso (Rusche; Kirchheimer, 1984, p. 72), ${ }^{70}$ ya que, en muchas oportunidades, por lo menos dentro del contexto nacional, los programas de reeducación son insufi-

${ }^{68}$ Para el caso colombiano, ver el artículo $4^{\circ}$ del CP, que consagra los siguientes fines: prevención general, retribución justa, prevención especial, reinserción social y protección al condenado.

${ }^{69}$ En el mismo sentido, ver Ferrajoli (2009, p. 263) y Roxin (1997, p. 93).

70 "La resocialización e inserción social, por lo menos en lo que concierne a América Latina y específicamente a Colombia, es de carácter discursivo, en la medida en que no hay una correspondencia real u operativización clara y precisa de las acciones que se implementen para su consecución, dado que aún persiste la concepción de la política criminal antigua en el funcionamiento real del sistema penitenciario (Universidad Nacional de Colombia-INPEC 2012, p. 122). 
cientes $^{71}$ o poco efectivos, cumpliendo la pena otras funciones distintas a la especialmente encomendada por el constituyente y los legisladores durante esta fase del proceso. ${ }^{72}$ En este sentido, se perpetúan los fines retributivos y neutralizadores (Baratta, 1990, p. 2), dentro de un proyecto "securitario" (Sozzo, 2007, p. 104), que fácilmente se cumple en las condiciones del sistema penitenciario colombiano, junto con el llamado de atención a la sociedad para evitar la comisión de delitos y ratificar la confianza en la vigencia de la norma. Es decir, que se persiguen los fines respecto de quienes no han delinquido (Zaffaroni; Alagia; Slokar 2000, p. 53), junto con aquellos negativos que recaen en cabeza del condenado, sacrificando su corrección. ${ }^{73}$ En este contexto, muchos consideran que, en el sistema penitenciario colombiano, la resocialización ocupa un lugar subalterno, convirtiéndose la cárcel en una herramienta de venganza pública que se utiliza para devolver la confianza en la justicia penal (Fernández, 2010, p. 92).

Dentro del sistema penal colombiano, la respuesta favorita del legislador, ante la trasgresión de los bienes jurídicos tutelados a través de la comisión de delitos, ha sido el encarcelamiento, como muestran los datos estudiados en el cuerpo de este trabajo.

71 Dentro del sistema penitenciario español, también se ㄱ. hace esta crítica (González, 2012, pp. 369-371).

72 En el mismo sentido, ver la sentencia C-261 de 1996 ,

M.P. Alejando Martínez Caballero, que, al respecto, señala:

œ "Sin embargo, a pesar de esas inevitables tensiones y dis-

o cusiones, lo cierto es que, durante la ejecución de las pe-

10 nas, debe predominar la búsqueda de resocialización del

ó delincuente, ya que esto es una consecuencia natural de la

is definición de Colombia como un Estado social de derecho

$\therefore$ fundado en la dignidad humana (CP art. $1^{\circ}$ ), puesto que

$\therefore$ el objeto del derecho penal, en un Estado de este tipo, no

$\varpi$ es excluir al delincuente del pacto social, sino buscar su

¿ reinserción en el mismo. Por ello, es lógico que los instru-

- mentos internacionales de derechos humanos establezcan

^ esa función resocializadora del tratamiento penitenciario.

$>$ Así, de manera expresa, el artículo 10 numeral $3^{\circ}$ del Pacto

ธิ de Derechos Civiles y Políticos de las Naciones Unidas,

T aprobado por Colombia por la Ley 74 de 1968, consagra

$\geq$ que el régimen penitenciario consistirá en un tratamiento

๙ cuya finalidad esencial será la reforma y la readaptación

- social de los penados". Congruentes con lo anterior, ver

las sentencias C-144 de 1997, M.P. Alejando Martínez Ca-

ballero, T-528 de 2000, M.P. Fabio Morón Díaz y C-194 de

尺 2005, M.P. Marco Gerardo Monroy Cabra.

到 ${ }^{73}$ En el mismo sentido, ver Garland (2005, pp. 42, 51 y ษ 287).
No obstante lo anterior y advirtiendo que el objetivo de este trabajo no estaba circunscrito a criticar la legitimidad de la cárcel como institución, sino a indagar, si dentro de la misma, puede llevarse a cabo el proyecto de resocialización - como mandato legalmente establecido, siguiendo los instrumentos internacionales que regulan la materia y hacen parte del bloque de constitucionalidad -, los resultados encontrados, no son positivos. Desde la base del tratamiento penitenciario, que corresponde a las diferentes fases por las que asciende progresivamente el condenado, existen impedimentos para concretar la resocialización, ya que, según lo afirmado por el Ministerio de Justicia y del Derecho, la labor del CET es parsimoniosa, por carencia de personal especializado e incluso por escasez de implementos de secretaria, lo que conlleva a que muchos internos no puedan superar las fases de mayor seguridad para lograr a así acceder a permisos y programas de resocialización.

Adicionalmente y como se observa en los hallazgos, tanto la infraestructura como el personal destinado para los programas de resocialización son insuficientes o mal capacitados, teniendo incluso los condenados, en algunas oportunidades, que suplir la ausencia de capacitadores al interior de los distintos programas. Tampoco cuentan con los implementos necesarios para adelantar las actividades de resocialización habilitadas en el respectivo penal. A su vez, los programas ofertados no son los más adecuados para preparar su retorno a la libertad. Esto se agrava dentro del contexto de hacinamiento narrado al interior de este trabajo, en donde ante la imposibilidad de participar en los programas de resocialización (Ver Tabla 2), al interno no le queda otro camino que inscribirse en los cursos informales de la universidad del delito, que siempre cuenta con cupos disponibles. De conformidad con lo anterior, la situación de hacinamiento no solo dificulta la vida de la persona condenada al interior de los muros carcelarios, sino que también imposibilita su desarrollo personal por 
fuera de ellos y lo invita al retorno, ante la inevitable tentación de la reincidencia, motivada por la falta de oportunidades y la ausencia de concientización de los parámetros socialmente establecidos.

En materia de redención de pena y beneficios administrativos, se encuentra el interno con el obstáculo burocrático, que, en oportunidades, genera una tal anquera desde el mismo establecimiento de reclusión que no realiza los trámites necesarios para que se estudie su situación. Cuando los hace, la suerte del interno queda en manos de un Juez de Ejecución de Penas y Medidas de Seguridad, que, en virtud de la expansión del sistema, cuenta con una carga significativa de trabajo y no resuelve oportunamente las solicitudes que hacen las personas que se encuentran privadas de la libertad.

La insuficiencia institucional traspasa las fronteras del perímetro carcelario. Debido a la crisis del sistema que imposibilita la implementación de programas al interior de la cárcel, sería osado esperar el seguimiento del condenado una vez recobre la libertad. A pesar que existen directivas al respecto, pero se carece de recursos para su implementación (Colombia, 2014, p. 79). No quiere esto decir que la imposibilidad fáctica se corresponda con la finalidad perseguida, ya que el proceso de resocialización requiere de un acompañamiento intramuros y extramuros, este último olvidado dentro del contexto colombiano. De esta manera, el individuo afronta la sociedad como un huérfano más, que, en virtud del encarcelamiento, pudo haber roto los escasos lazos con que contaba y se enfrenta al rechazo de la sociedad por su pasado penal, lo que le dificultará la consecución de un trabajo y lo llevará hacia al delito, con el riesgo profesional de volver a la cárcel, ratificándose, de esta manera, el fracaso de la resocialización.

Recebido para publicação em 20 de maio de 2016 Aceito em 25 outubro de 2017

\section{REFERENCIAS}

ACOSTA, D. Sistema integral de Tratamiento Progresivo Penitenciario: Reflexión en torno a la construcción de un modelo de atención a internos. Bogotá: INPEC, 1996.

ALBINYANA, J.; CERVERA, S. Vida en prisión: guía práctica de derecho penitenciario. Madrid: Fe d'erratas, 2014.

ANTONY, C. Mujeres invisibles: las cárceles femeninas en América Latina. Nueva Sociedad, San José, n. 208, p. 7385, 2007.

ARIZA, L. Reformando el infierno: los tribunales y la transformación del campo penitenciario en América Latina. In: ARIZA, L.; ITURRALDE, M. Los muros de la infamia. Prisiones en Colombia y en América Latina. Bogotá: Universidad de los Andes, 2011. p. 18-108.

ARIZA, L.; ANGEL, C. En el corazón del buen pastor: la apropiación del discurso de los derechos humanos en el contexto penitenciario colombiano. Revista de antropología y arqueología, Bogota, n. 23, p. 45-64, 2015.

ARIZA, L.; ITURRALDE, M. Una perspectiva general sobre mujeres y prisiones en América Latina y Colombia. Revista de derecho público, Santiago de Chile, n. 35, p. 1-25, 2015.

ARIZA, L.; ZAMBRANO, R. Cárcel Kapuría. Las rutas del encarcelamiento de indígenas en Colombia. Revista jurídica de la Universidad de Palermo, Buenos Aires, año 13, n. 1, p. 157-181, 2012.

BARATTA, A. Resocialización o control social: por un concepto crítico de "reintegración social" del condenado. Ponencia presentada en el seminario "Criminología crítica y sistema penal", organizado por Comisión Andina Juristas y la Comisión Episcopal de Acción Social. Lima, del 17 al 21 de Septiembre de 1990. Traducción de Mauricio Martínez. Disponible en: <http://perso.unifr.ch/derechopenal/assets/files/ articulos/a_20120608_01.pdf $>$. Acceso en: 20 mayo 2016).

BARATTA, A. Criminología crítica y crítica del derecho penal. México: Siglo XXI editores, 1989.

BIRCKECK, C. Tres enfoques necesarios para la victimología. Revista Cenipec, Mérida, n. 22, p. 33-66, 2003

CARLEN, P.Women's imprisonment. A study in social control. London: Routledge \& Kegan Paul, 1983.

CARRANZA, E. Situación penitenciaria en América Latina y el Caribe ¿Qué hacer? Anuario de derechos humanos, Santiago, n. 8, p. 31-66, 2012.

CERVELLÓ, V. Las prisiones de mujeres desde una perspectiva de género. Revista General de Derecho Penal, [S.l.], n. 5, p. 1-24, 2006.

CHRISTIE, N. La industria del control del delito: ¿La nueva forma del holocausto? Traducción de Sara Costa. Buenos Aires: Editores del Puerto, 1993.

CID, J. La elección del castigo. Barcelona: Bosch, 2009.

CID, J. El sistema penitenciario en España. Jueces para la democracia, [S.l.], n. 45, p. 15-27, 1999.

CLEMMER, D. The Prison Community. New York: Rinehart \& Winston, 1958.

COYLE, A. Understanding prisons: Key issues in policy and practice. Glasgow: Open UniversityPress, 2005.

CRESPO, F; BOLAÑOS, M. Código del preso: acerca de los efectos de la subcultura del prisionero. Capítulo criminológico, v. 37, n. 2, p. 53-75, 2009.

CREWE, B. Prison culture and the prisoner society. En: CREWE, B.; BENNET, J. (Ed.). The prisoner. Oxford: Routledge, 2012. p. 17-45. 
CULLEN, F.; GILBERT, K. Reaffirming Rehabilition. Cincinnati: Anderson Publishing, 1982.

DEJONG, C. Survival Analysis and Specific Deterrence: Integrating Theoretical and Empirical Models of Recidivism. Criminology, Columbus, v. 35 , n. 4, p. 561575, 1997.

DORADO, P. El derecho protector de los criminales. Madrid: Librería General de Victoriano Suárez, 1915.

ECHEVERRI, J. La prisionalización, sus efectos psicológicos y su evaluación. Pensando Psicología, Envigado, v. 6, n. 11, p.157-166, 2010.

FERNÁNDEZ, W. Derechos fundamentales en el actual sistema penal acusatorio. En: POSADA, J. (Ed.). III Simposio Internacional Penitenciario y de Derechos Humanos. Medellín: Universidad de San Buenaventura, 2010. p. 87-92.

FERRAJOLI, L. Derecho y razón: Teoría del garantismo penal. Madrid: Trotta, 2009.

FOUCAULT, M. Vigilar y castigar: Nacimiento de la prisión. Buenos Aires: Siglo XXI Editores, 1976.

GARCÍA, C. El panóptico de Bentham. Revista de Estudios Penitenciarios, Madrid, n. 129, p. 570-599 1957.

GARCIA- BORÉS, J. El impacto carcelario. En: BERGALLI, R.(Coord.) Sistema penal y problemas sociales. Valencia: Tirant to Blanch, 2003. p. 362-404

GARCIA-PABLOS MOLINA, A. La supuesta función resocializadora del derecho penal: utopía, mito e eufemismo. Anuario de derecho penal y ciencias penales, Madrid, t. 32, Fasc. 3, p. 645-700, 1979.

GARLAND, D La cultura del control Crimen y orden social en la sociedad contemporánea. Traducción de M. Sozzo. Barcelona: Gedisa, 2005.

GEREZ, M. Estrategias discursivas y políticas del dispositivo punitivo. En: CONGRESO INTERNACIONAL DE INVESTIGACIÓN Y PRÁCTICA PROFESIONAL EN PSICOLOGIA, 1.; XVI JORNADAS DE INVESTIGACIÓN QUINTO ENCUENTRO DE INVESTIGADORES EN PSICOLOGÍA DEL MERCOSUR, 16., 2009, Buenos Aires. Acta... Buenos Aires: Facultad de Psicología - Universidad de Buenos Aires, 2009. p. 511-514.

GIORDANO, P.; CERNKOVICH, S.; RUDOLPH, J. Gender Crime and Desistance: Toward a Theory of Cognitive Transformation. The American Journal of Sociology, - Chicago,v. 107, n. 4, p. 990-1064, 2002.

อำ . GONZÁLEZ SÁNCHEZ, I. La cárcel en España. Mediciones $\dot{\mathrm{N}} \mathrm{y}$ condiciones del encarcelamiento en el siglo XXI. Revista

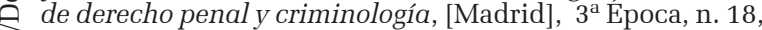
p. 351-402, 2012.

o GUILLAMONDEGUI, L. Resocialización y semilibertad. is Buenos Aires: Editorial B de F, 2010.

के HERNÁNDEZ, N. El pago de la multa y la ley 1709 de is 2014. Análisis de la libertad condicional y los sistemas

$\dot{2}$ de vigilancia electrónica antes del tránsito legislativo.

- Sistema penal \& Violencia, Porto Alegre, v. 7, n. 1, p. 116-

$\infty 141,2015$

¿ ITURRALDE, M. Prisiones y castigo en Colombia: La construcción de un orden social excluyente. En: ARIZA,

$>$ L.; ITURRALDE, M. Los muros de la infamia: Prisiones en

ö Colombia y América Latina. Bogotá: Universidad de los Andes, 2011. p. 110-194

LARRAURI, E. Introducción a la criminología y al sistema penal. Madrid: Trotta, 2015.

승 LASTRES, F. Estudios Penitenciarios. Madrid: Jiménez Gil Editor, 1887.

LIEBLING, Al.; PRICE, D.; SHEFER, G. The prison officer. Londres: Routledge, 2011.
LIEBLING, A.; ARNOLD, H. Prisons and their Moral Performance: A Study of Values, Quality, and Prison Life. Oxford: Oxford UniversityPress, 2004.

LUZÓN, D. M. Medición de la pena y sustitutivos penales. Madrid: Instituto de Criminología de la Universidad Complutense de Madrid, 1979.

MANDELA, N. Long Walk to Freedom. London: Little Brown \& Company, 1994.

MATTHEWS, R. Una propuesta realista de reforma para las prisiones de Lationamérica. Politica criminal, Santiago, v. 6, n. 12 , p. 296-338, 2011.

MATTHEWS, R. Pagando tiempo: Una introducción a la sociología del encarcelamiento. Barcelona: Bellaterra, 2003.

MELOSSI, D.; PAVARINI, M. Cárcel y fábrica: Los orígenes del sistema penitenciario (Siglos XVI-XIX). Traducción de Xavier Massimi. México: Siglo XXI editores, 1987.

MIR PUIG, S. ¿Qué queda en pie de la resocialización? Eguzkilore, [S.1.], n. 2, p. 35-41, 1989. Número extraordinadio.

MUÑOZ CONDE, F. La resocialización del delincuente: Análisis y crítica de un mito. En: MIR, S. (Ed.). Política criminal y reforma del derecho penal. Bogotá: Temis, 1982. p. 131-154.

NORZA, E. et al. Descripción de la criminalidad femenina en Colombia: factores de riesgo y motivación criminal. Criminalidad, Bogotá, v. 54, n. 1, p. 339-357, 2012.

PÉREZ, W. ¿Nos repugna realmente la prisión? Un recordatorio abolicionista. Revista diálogos de derecho y política, Medellín, n. 8, ãno 3, p. 1-18, 2012.

RODRÍGUEZ, C. ¿Cuándo cesa el estado de cosas inconstitucional del desplazamiento? Más allá del desplazamientoo como superar un estado de cosas inconstitucional. En: RODRIGUEZ, C. (Coord.). Más allá del desplazamiento: Políticas, derechos y superación del desplazamiento forzado en Colombia. Bogotá: Universidad de los Andes, 2010.

ROXIN, C. Derecho Penal, Parte General. Madrid: Civitas, 1997

RUEDA, M. Función de ejecución de penas y medidas de seguridad. Bogotá: Consejo Superior de la Judicatura (Sala Administrativa) y Escuela Judicial Rodrigo Lara Bonilla, 2010.

RUSCHE, G.; KIRCHHEIMER, O. Pena y estructura social. Traducción de Emilio García. Bogotá: Temis, 1984.

SAMPEDRO, J. Apuntes sobre la resocialización en el sistema penitenciario colombiano. Eguzkilore, n. 12, p. 107-111, 1998. Número extraordinadio.

SAMPSON, R.; LAUB, J. Crime in the Making: Pathways and Turning Points through Life. Cambridge: Harvard University Press, 1993

SPARKS, R.; BOTTOMS, A.; HAY, W. Prisons and the Problem of Order. Oxford: Clarendon Press, 1996.

SOZZO, M. ¿Metamorfosis de la prisión? Proyecto normalizador, populismo punitivo y "prisión-depósito". Revista Latinoamericana de Seguridad ciudadana, Quito, n. 1, p. 88-116, 2007.

SYKES, G. The society of captives: A study of a maximum security prison. Princeton: Princeton University Press, 1997.

SYKES, G.; MESSENGER, S. The Inmates social system. En: CLOWARD, Richard A. Theorical studies in social organization of the prison. United States of America: Social Science Research Council, 1960. p. 5-20,

TÈLLEZ, A. Derecho penitenciario colombiano: Un aproximación desde la experiencia española. Anuario de derecho penal y ciencias penales, Madrid, v. 49, n. 2, p. 591-625, 1996. 
URÍAS, J. El valor constitucional del mandato de resocialización. Revista española de derecho constitucional, Madrid, n. 63, p. 43-78, 2001.

ZAFFARONI, E.; ALAGIA, A.; SLOKAR, A. Derecho Penal: Parte General. Buenos Aires: Ediar, 2000.

\section{JURISPRUDENCIA}

COLOMBIA, Rama Judicial del Poder Público, Corte Constitucional, Sentencia T-601 de 1992, M.P. Eduardo Cifuentes Muñoz.

COLOMBIA, Rama Judicial del Poder Público, Corte Constitucional, Sentencia C-394 de 1995, M.P. Vladimiro Naranjo Mesa.

COLOMBIA, Rama Judicial del Poder Público, Corte Constitucional, Sentencia C-261 de 1996, M.P. Alejando Martínez Caballero.

COLOMBIA, Rama Judicial del Poder Público, Corte Constitucional, Sentencia C-144 de 1997, M.P. Alejando Martínez Caballero.

COLOMBIA, Rama Judicial del Poder Público, Corte Constitucional, Sentencia T- 153 de 1998, M.P. Eduardo Cifuentes Muñoz

COLOMBIA, Rama Judicial del Poder Público, Corte Constitucional, Sentencia T-528 de 2000, M.P. Fabio Morón Díaz.

COLOMBIA, Rama Judicial del Poder Público, Corte Constitucional, Sentencia T-847 de 2000, M.P. Carlos Gaviria Díaz.

COLOMBIA, Rama Judicial del Poder Público, Corte Constitucional, Sentencia T-1670 de 2000, M.P. Carlos Gaviria Díaz.

COLOMBIA, Rama Judicial del Poder Público, Corte Constitucional, Sentencia C-157 de 2002, M.P. Manuel José Cepeda Espinosa.

COLOMBIA, Rama Judicial del Poder Público, Corte Constitucional, Sentencia T-025 de 2004, M.P. Manuel José Cepeda Espinosa.

COLOMBIA, Rama Judicial del Poder Público, Corte Constitucional, Sentencia T-1096 de 2004, M.P. Manuel José Cepeda Espinosa.

COLOMBIA, Rama Judicial del Poder Público, Corte Constitucional, Sentencia C-194 de 2005, M.P. Marco Gerardo Monroy Cabra.

COLOMBIA, Rama Judicial del Poder Público, Corte Constitucional, Sentencia T-274/05, M.P. Humberto Antonio Sierra Porto

COLOMBIA, Rama Judicial del Poder Público, Corte Constitucional, Sentencia T-1093 de 2005, M.P. Clara Inés Vargas Hernández

COLOMBIA, Rama Judicial del Poder Público, Corte Constitucional, Sentencia T- 1275/05, M.P. Humberto Antonio Sierra Porto

COLOMBIA, Rama Judicial del Poder Público, Corte Constitucional, Sentencia T- 393/08, M.P. Humberto Antonio Sierra Porto.

COLOMBIA, Rama Judicial del Poder Público, Corte Constitucional, Sentencia T- 412 de 2009, M.P. Maria Victoria Calle Correa.

COLOMBIA, Rama Judicial del Poder Público, Corte Constitucional, Sentencia T-572/09, M.P. Humberto Antonio Sierra Porto.
COLOMBIA, Rama Judicial del Poder Público, Corte Constitucional, Sentencia T-429 de 2010, M.P. Juan Carlos Henao Pérez.

COLOMBIA, Rama Judicial del Poder Público, Corte Constitucional, Sentencia T-286 de 2011, M.P. Jorge Ignacio PreteltChaljub.

COLOMBIA, Rama Judicial del Poder Público, Corte Constitucional, Sentencia T-213 de 2011, M.P. Gabriel Eduardo Mendoza Martelo.

COLOMBIA, Rama Judicial del Poder Público, Corte Constitucional, Sentencia T- 338 de 2013, M.P. Maria Victoria Calle Correa.

COLOMBIA, Rama Judicial del Poder Público, Corte Constitucional, Sentencia T-718/15, M.P. Jorge Iván Palacio.

COLOMBIA, Rama Judicial del Poder Público, Corte Constitucional, Sentencia T- 762 de 2015, M.P. Gloria Stella Ortíz Delgado.

COLOMBIA, Rama Judicial del Poder Público, Corte Suprema de Justicia, Sala Penal, Sentencia del 2 de julio de 2015 [STP-8442 (80488)], M.P. Jose Luis Barceló Camacho.

ESPAÑA. Tribunal Constitucional, Sentencia ATC 780/1986.

ESPAÑA. Tribunal Constitucional, Sentencia STC 2/1987.

ESPAÑA. Tribunal Constitucional, Sentencia STC 81/1997.

ESPAÑA. Tribunal Constitucional, Sentencia STC 75/1998

ESPAÑA. Tribunal Constitucional, Sentencia STC $91 / 2000$.

\section{NORMAS}

COLOMBIA. Asamblea Nacional Constituyente, Constitución Política de 1991.

COLOMBIA. Congreso de la República, Ley 65 de 1993 (Código Penitenciario y Carcelario.

COLOMBIA. Congreso de la República, Ley 599 de 2000 (Código Penal).

COLOMBIA. Congreso de la República, Ley 1098 de 2006 (Código de la Infancia y la Adolescencia).

COLOMBIA. Congreso de la República, Ley 1709 de 2014.

ESPAÑA. Cortes Generales, Constitución Española de 1978.

ITALIA, Asamblea Constituyente, Constitución Italiana de 1947.

INFORMES Y OTROS DOCUMENTOS

ALTO COMISIONADO DE LAS NACIONES UNIDAS PARA LOS DERECHOS HUMANOS. Informe Centros de reclusión en Colombia: Un estado de cosas inconstitucional y de flagrante violación de derechos humanos, 2001.

COLOMBIA. Consejo Nacional de Política Económica y Social - CONPES 3828. Política penitenciaria y carcelaria en Colombia, 2015

COLOMBIA. Defensoría del Pueblo. Informe: Análisis 
sobre el actual hacinamiento carcelario y penitenciario en Colombia, 2003.

COLOMBIA. Instituto Nacional Penitenciario y Cacelario - INPEC. Oficina asesora de Planeación. Grupo de estadística. Informe estadístico marzo de 2016.

COLOMBIA. Instituto Nacional Penitenciario y Cacelario INPEC. Resolución 7302 de 2005.

COLOMBIA. Instituto Nacional Penitenciario y Cacelario INPEC. Resolución 2392 de 2006.

COLOMBIA. Instituto Nacional Penitenciario y Cacelario INPEC. Resolución 8619 de 2013.

COLOMBIA. Ministerio de Justicia y del Derecho . Plan de desarrollo y rehabilitación del sistema penitenciario nacional. Bogotá: Imprenta Nacional de Colombia, 1989.

COLOMBIA. Ministerio de Justicia y del Derecho. Dirección de Política criminal y penitenciaria. Lineamientos parael fortalecimiento de la política penitenciaria en Colombia. Bogotá: CYE Consult, 2014.
GRUPO DE DERECHO DE INTERÉS PÚBLICO. Situación carcelaria en Colombia: Informe sombra presentado al CDH de las Naciones Unidas en respuesta al sexto informe de Colombia. Documento de trabajo \# 1. Bogotá: Universidad de los Andes, 2010.

ORGANIZACIÓN DE NACIONES UNIDAS. Asamblea General, resolución $43 / 173$, de 9 de diciembre de 1988, Conjunto de Principios para la protección de todas las personas sometidas a cualquier forma de detención o prisión

UNIVERSIDAD NACIONAL DE COLOMBIA. Instituto Nacional Penitenciario y Carcelario - INPEC. Estados de arte de los procesos de evaluación y caracterización de la población interna. Convenio interadministrativo n. $138 \mathrm{de}$ 2011. Director-Editor: José Ignacio Ruiz Pérez, 2012. 


\section{RESOCIALIZATION AS END OF SENTENCE - A frustration with the Colombian penitentiary and prison system}

\author{
Norberto Hernández Jiménez
}

This article analyses resocialization as the main finality of deterrent sentencing in Colombia during its execution phase. To this end, the article contextualizes the difficult situation that the penitentiary and prison systems of Colombia withstand, which, as the Constitutional Court declared, constitutes an institutional situation that compromises the human dignity of deterred persons. Within this reality - comprising a significant prison overcrowding, which, in its turn, fosters an environment of violence, corruption and inequality -, offers and access to resocialization programs are scarce, impeding the rehabilitation of individuals. This context hinders the fulfilling of this finality, for it is observed that a great percentage of released felons returns to prison, configuring the phenomenon of recidivism.

KEywords: Resocialization. Ends of sentence. Prison overcrowding. Recidivism.

\section{LA RESOCIALISATION COMME FIN DE PEINE - Une frustration dans le système pénitentiaire et à l'univers carcéral en Colombie}

\author{
Norberto Hernández Jiménez
}

Dans cette recherche, la resocialisation est analysée en tant qu'objectif principal de la peine de détention en Colombie pendant sa phase d'exécution. Pour ce faire, il faut remettre en contexte la situation difficile dans laquelle se trouve le système pénitentiaire et carcéral colombien. Comme l'a déclaré la Cour Constitutionnelle, il se caractérise par une situation institutionnelle où la dignité humaine des personnes privées de liberté est gravement compromise. Au sein de cette réalité, qui inclut un surpeuplement carcéral important favorisant lui-même un environnement de violence, de corruption et d'inégalité, l'offre et l'accès aux programmes de resocialisation sont limités, ce qui est une entrave à la réadaptation de l'individu. Le défi qui consiste à réaliser cet objectif n'est pas atteint car on observe qu'un pourcentage important de détenus retourne en prison, ce qui caractérise un phénomène de récidive.

Mots-CLÉs: Resocialisation. Finalités de la punition. Surpeuplement carcéral. Récidive.

Norberto Hernández Jiménez - Docente investigador y miembro del grupo de investigación en derecho penal, derecho disciplinario y derechos humanos de la Universidad Libre (Bogotá). Director del Consultorio Jurídico de la Universidad de los Andes (Bogotá) y Asesor del Grupo de prisiones de la misma Universidad. Abogado, especialista y magíster en derecho penal de la Universidad Libre (Bogotá). Especialista en derecho constitucional y en derecho administrativo de la Universidad del Rosario (Bogotá). Máster en criminología y ejecución penal de la Universitat Pompeu Fabra (Barcelona). Doctor en Derecho por la Universidad de los Andes (Bogotá). Sus temas de investigación son derecho penal, derecho procesal penal, criminología y justicia transicional. 
